\title{
EN BÚSQUEDA DEL MATCH PERFECTO. PERFILES, EXPERIENCIAS Y EXPECTATIVAS SOCIOAFECTIVAS DE JÓVENES EN TORNO A TINDER
}

\author{
JOAQUÍN LINNE ${ }^{1}$ \\ PAULA FERNÁNDEZ LOPES ${ }^{2}$
}

«-iInternet! -dijo Tom resoplando-. Internet sólo refleja lo que ya está en la mente humana. Quizá un poco menos».

(Lorrie Moore, Gracias por la compañía).

\section{RESUMEN}

Este trabajo explora y describe perfiles y estrategias que construyen, especialmente, jóvenes de sectores medios del Área Metropolitana de Buenos Aires (AMBA) en la aplicación geosocial Tinder, orientada a la búsqueda de contactos sexoafectivos entre personas geográficamente cercanas. A nivel metodológico, se crearon dos cuentas ad hoc con las que se realizó una etnografía virtual en la que se analizaron 1.500 perfiles y se entrevistaron a 20 usuarios. Entre los resultados, se distinguen tres tipos de perfiles, según el capital más destacado: económico, cultural o erótico. En el primero, asociado al capital económico, se enfatizan las imágenes y textos

\footnotetext{
${ }^{1}$ Sociólogo, Doctor en Ciencias Sociales por la Universidad de Buenos Aires (UBA). Investigador del CONICET con sede en el Instituto Gino Germani y Docente de la UBA. Correo electrónico: joaquinlinne@gmail.com

${ }^{2}$ Socióloga, Doctoranda por la Universidad de Buenos Aires (UBA). Investigadora en formación del CONICET con sede en el Instituto Gino Germani y docente de la UBA. Correo electrónico: paula_dafer@hotmail.com
} 
personales que exhiben bienes distinguidos, en particular capital turístico, y se señala que viajar es su principal hobby, pasión o aspecto identitario. En el segundo, centrado en el capital cultural, se mencionan títulos terciarios o universitarios obtenidos o en curso, se alude a idiomas que se dominan, se utilizan expresiones en inglés y se enumeran consumos culturales frecuentes. En el último, focalizado en el capital erótico, los recursos visuales y textuales se concentran en construir una corporalidad deseada mediante la representación de atributos físicos seductores y de hábitos deportivos y saludables. Para esto, se presentan prácticas vinculadas a actividades físicas de moda o a hábitos relacionados con filosofías alternativas o new age. Por último, por un lado, se postula que las elecciones sexoafectivas tienden a equipararse a elecciones inmediatas de consumo; por otro, que la gestión del yo, vinculada a la exhibición regulada y calculada de sí mismo vía plataformas de redes sociales, se exacerba en las apps de citas, donde ya no solo se busca un «me gusta» generalizado, sino un concreto like de una pareja potencial.

PALABRAS ClAVE: INTERNET, TIC, REDES SOCIALES, TINDER, JÓVENES, GÉNERO, SEXOAFECTIVIDAD, ETNOGRAFÍA VIRTUAL

\title{
NA PROCURA DO MATCH PERFEITO. PERfIS, EXPERIÊNCIAS E EXPECTATIVAS SOCIOAFETIVAS DOS JOVENS EM TORNO DO TINDER
}

\begin{abstract}
RESUMO
Este trabalho explora e descreve perfis e estratégias que são construídos, especialmente por jovens dos setores médios da Área Metropolitana de Buenos Aires (AMBA) no aplicativo geossocial Tinder, orientado para a procura de contatos sexoafetivos entre pessoas geograficamente próximas. No nível metodológico, foram criadas duas contas ad hoc com as quais foi realizada uma etnografia virtual na que foram analisados 1.500 perfis e entrevistados 20 usuários. Entre os resultados, foram distinguidos três tipos de perfis, segundo o capital mais destacado: econômico, cultural e erótico. No primeiro, associado ao capital econômico, são destacadas as imagens e textos pessoais que exibem bens elegantes, em particular o capital turístico, indicando que viajar é o seu principal hobby, paixão ou aspecto identitário. No segundo, centrado no capital cultural, são mencionados títulos terciários ou
\end{abstract}


universitários obtidos ou em andamento, indicando os idiomas que dominam, as expressões em inglês utilizadas e a enumeração dos consumos culturais frequentes. No último, focalizado no capital erótico, os recursos visuais e textuais se concentram na construção de uma corporalidade desejadas por meio da representação de atributos físicos sedutores e de hábitos esportivos e saudáveis. Para isto, são apresentadas práticas relacionadas às atividades físicas na moda ou hábitos relacionados com filosofias alternativas ou new age. Por último, por um lado postulamos que as escolhas sexoafetivas tendem a ser equiparadas às escolhas imediatas de consumo; por outro lado, que a gestão do eu, ligada à exibição regulada e calculada de si mesmo via plataformas de redes sociais, é exacerbada nos aplicativos de encontros, onde já não é procurado apenas um "curtir" generalizado, senão um concreto like de um potencial casal.

PALAVRAS-CHAVE: INTERNET, TIC, REDES SOCIAIS, TINDER, JOVENS, GÊNERO, SEXOAFETIVIDADE, ETNOGRAFIA VIRTUAL

\title{
LOOKIng for the PERfect MATCH. Profiles, EXPERIENCES AND SOCIO-AFFECTIVE EXPECTATIONS OF YOUNG INDIVIDUALS ON TINDER
}

\begin{abstract}
This work explores and describes the profiles and strategies created by, especially, middle-class young individuals from Buenos Aires Metropolitan Area (BAMA) on the geo-social application Tinder to look for sexual and affective contacts among geographically close people. On the methodological level, the data was obtained through two ad hoc accounts, which were used to carry out a virtual ethnography that analyzed 1.500 profiles, and 20 interviews conducted to users. The results were, that three types of profiles can be distinguished, in accordance to their most prominent capital (economic, cultural or erotic). In the first, the economic capital profile highlights images and personal texts showing elegant goods, particularly tourism capital, and states traveling as their main hobby, passion or identity mark. The second type, the cultural capital, is characterized by showing off higher education or university degrees, referring to languages mastered, by using expressions coming from English and by referring to frequent cultural consumption.
\end{abstract}


In the last one, the erotic capital, textual and visual resources are focused on building a desirable corporality through portraying seductive physical and/or healthy attributes and habits, through trendy physical activities or habits related to alternative or new age philosophies. Finally, on the one hand, it is stated that sex-affective choices tend to be equaled to immediate consumption choices; on the other hand, that the management of 'I', linked to a regulated, calculated exhibition of themselves through social networks, exacerbated on dating apps, where the general 'like' is not the only most sought-after reaction; instead, a specific like from a potential new couple is especially sought-after.

KEYWORDS: INTERNET, TICS, SOCIAL NETWORK, TINDER, YOUNG INDIVIDUALS, GENDER, SEX-AFFECTIVITY, VIRTUAL ETHNOGRAPHY

\section{INTRODUCCIÓN}

En reuniones de grupos de amigos y amigas jóvenes, las apps (aplicaciones) «para conocer gente» son un tema de conversación habitual. Es común que quienes las utilizan se jacten de sus experiencias y quienes no las usan pregunten cómo funcionan. Mantienen varios chats al mismo tiempo, arreglan «microcitas» (encuentros de una o dos horas que sirven para no «perder» toda la noche del sábado si no hay afinidad) y cancelan citas a último momento porque «les surgió una mejor». En ocasiones, es frecuente que compitan entre sí por ver quién obtuvo más citas o que se adviertan al descubrirse demasiado ensimismados en su uso. Incluso en citas orquestadas a través de estas apps, en bares, restaurants o discotecas, suelen chatear, revisar actualizaciones en sus redes y gestionar futuros encuentros con otros contactos. La búsqueda de match perfecto nunca se detiene.

Tinder, entre las denominadas apps de citas, dating apps o love apps, es la más utilizada, tanto a nivel global como regional y local. Lanzada en 2012, adquirió rápidamente popularidad global, con nueve billones de matches desde su inicio, un promedio de doce millones de matches diarios. Además, es la plataforma más popular de búsqueda de citas basada en la geolocalización de usuarios. En la actualidad, cuenta con alrededor de 56 
millones de usuarios activos en 196 países, se encuentra disponible en 40 idiomas y al menos la mitad de sus usuarios son menores de 35 años (Ward, 2017).

A diferencia de sitios de búsqueda de contactos sexoafectivos como la pionera Match.com, Tinder se utiliza mayormente como app para teléfonos móviles ${ }^{3}$. Con más de un billón de swipes diarios («deslizamiento» de perfiles), Tinder fue pionera como swiping app, otorgándoles a los usuarios ese efecto que combina poder lúdico y zona de confort. Deslizando sobre la pantalla un dedo hacia la derecha, pueden darles like a los perfiles deseados, y con solo un deslizamiento a la izquierda, pueden descartar un perfil. Si dos usuarios se dan like entre sí, se crea un match y solo entonces pueden comenzar a chatear.

La app es de uso accesible e intuitivo para la mayoría: solicita crear un perfil a partir de la cuenta de Facebook o del número de teléfono personal. Además, puede vincularse con las cuentas de Instagram y Spotify. En configuración, debe especificarse el máximo de distancia deseado para la búsqueda (de 1 a 161 kilómetros), así como el rango etario (a partir de los 18 años). Su geolocalizador indica a cuántos kilómetros se encuentra el contacto.

¿Cuáles son los perfiles más habituales? ¿Cómo filtran sus búsquedas $\operatorname{los}^{4}$ jóvenes del Área Metropolitana de Buenos Aires (AMBA)? ¿Qué tipos de información proporcionan? ¿Qué vínculos buscan y cuáles son sus expectativas en la $a p p$ ? ¿Qué experiencias sexoafectivas han tenido a partir de su uso? En esta investigación exploratoria indagamos perfiles de varones

\footnotetext{
${ }^{3}$ En el mercado de estas apps, también se destaca Happn, que muestra a usuarios que se cruzan geográficamente, señalando cuántas veces se cruzaron entre sí y dónde; Okcupid, que permite especificar intereses sexogenéricos; Match, primera app — paga - para búsqueda de citas, que brinda mayor privacidad y también permite refinar búsquedas; Grindr, centrada en gays y bisexuales, y Badoo, utilizada mayormente en sectores populares. Bumble, que permite que solo las mujeres inicien chats, todavía tiene un uso restringido a Estados Unidos.

${ }^{4} \mathrm{Si}$ bien en este artículo se utiliza por momentos el masculino como genérico, no desconocemos los debates en la materialidad misma de las palabras y los usos del llamado «lenguaje inclusivo», que nos interpelan para seguir pensando y construyendo no solo nuestras investigaciones, sino las relaciones mismas que esas investigaciones establecen con los signos y sentidos.
} 
y mujeres cis-heterosexuales que utilizan Tinder, así como en las percepciones y prácticas de sus usuarios.

\section{MATERIAL Y MÉTODOS}

Continuando con investigaciones previas en las que hemos abordado usos juveniles de Facebook (Linne, 2016), este artículo centra su análisis en las autodescripciones que realizan usuarios de Tinder residentes del AMBA, en un rango etario de 18 a 40 años. Las autodescripciones en Tinder son optativas y suelen consistir en un párrafo que acompaña a las imágenes personales. El objetivo consiste en describir y analizar ciertas tendencias sociales en esta población, teniendo en cuenta variables como el género, la edad y el nivel socioeconómico.

Realizamos una «etnografía virtual» (Hine, 2012) a partir de la creación de dos perfiles ad hoc en Tinder: uno de un usuario varón y otro de una usuaria mujer, con fotos personales. La muestra consiste en 1.500 perfiles de jóvenes varones y mujeres que declaran tener entre 18 y 40 años y residir en el AMBA. Durante 2018 observamos y analizamos la información de estos perfiles a partir de sus imágenes y textos publicados. Esto fue complementado con veinte entrevistas: diez realizadas desde el chat de la app y desde Whatsapp; diez de modo copresencial.

Se excluyó de la muestra a aquellos usuarios que, si bien se encontraban dentro de esta área, eran extranjeros, no residían permanentemente allí o no se autopercibían como cis-mujeres o cis-varones heterosexuales (Butler, 2005). Por razones éticas, se mantiene el anonimato de los perfiles y de los entrevistados, aclarando solo autopercepción de género y edad de los usuarios.

\section{ESTADO DE LA CUESTIÓN}

La juventud es una categoría compleja. Margulis y Urresti (1996) la entienden no solo vinculada a la edad, sino también al sector social, al género y a características histórico-culturales. De manera pionera, señalan que gran parte de las personas tratan de incorporar signos juveniles en pos de aumentar 
su estatus social, proceso que denominan «juvenilización».

Para comprender este proceso, es necesario abordar los cambios que favorecieron durante el siglo XX la transformación de una sexualidad reproductiva a una placentera. Al respecto, Foucault (2008) y Giddens (1995) aluden al desarrollo y al perfeccionamiento de métodos anticonceptivos, a la conquista de derechos sociales y laborales por parte de las mujeres y la comunidad LGBTI, lo cual implicó modificaciones en el cortejo y en los modos en que las parejas se conocen, se enamoran y gestionan proyectos en común. Illouz (2016) también incluye a la extensión global del movimiento feminista, que ha ejercido una significativa influencia en los cambios en la seducción, los roles, las representaciones y expectativas sexogenéricas de mujeres y varones.

En esta línea, Palumbo (2018) advierte tendencias asociadas a las relaciones sexoafectivas: mayor aceptación de diversas maneras de experimentar la sexualidad, una creciente reivindicación de autonomía personal, más control de las mujeres sobre la reproducción, avances legislativos en torno al colectivo de mujeres y diversidad sexual, así como una disminución en la tasa de natalidad y un aumento de jóvenes que prioriza sus carreras y actividades personales por sobre el «mandato» de construir una familia. La investigadora señala que las relaciones afectivas juveniles combinan guiones del amor romántico basados en fidelidad y posesión del otro con una búsqueda de mayor compañerismo e igualdad entre géneros, lo que implica replantear diversos aspectos de las relaciones.

Estos cambios también se encuentran atravesados por la expansión cotidiana de Internet. Beck y Beck-Gernsheim (2012) observan que estas tecnologías han modificado la configuración social del amor y sus protocolos, así como las estrategias desplegadas para establecer relaciones. Hasta hace unas décadas, la mayoría de las parejas se formaban en ámbitos cotidianos copresenciales, como la escuela, la universidad, el club, el barrio, el trabajo y las redes familiares y del grupo de pares. Durante los últimos años, estos espacios conviven con el auge de las apps, además de los sitios de redes sociales más populares como Facebook, Instagram, Snapchat y Twitter 
(Palumbo, 2018; Rosenfeld y Reuben, 2012). En definitiva, con la masificación de la Internet 2.0, ha crecido exponencialmente la cantidad de parejas que se conocen de modo virtual.

En este contexto, los lazos sociales y las identidades se despliegan con una lógica en la cual suele primar una ética de la instantaneidad. Existe cierta idea socialmente extendida de que resulta conveniente desarrollar relaciones «líquidas» (móviles) antes que «sólidas» (fijas) (Bauman, 2013). Esto explica en parte el crecimiento sostenido de estas apps, que habilitan una seducción más flexible, en el sentido de ubicua y asincrónica, que la tradicional. Como señala Palumbo (2018), estas apps proveen desde cualquier teléfono móvil acceso instantáneo a candidatos para tener experiencias sexoafectivas, permiten hiperracionalizar la delimitación de perfiles (por edad, género, distancia), modifican los escenarios de interacción y priorizan la superficie virtual por sobre la copresencial.

Estas tecnologías también operan sobre la subjetividad, fortaleciendo la idea de que la construcción, exhibición y gestión de la identidad online deben formar parte del ciudadano contemporáneo. Tal «mandato social» se observa con mayor intensidad entre los jóvenes (Boyd, 2014; Morduchowicz, 2012). Sibilia (2008) denomina este fenómeno «extimidad»; Marra e Rosa et al. (2016), «estetización del self»; nosotros, «multimidad» (Linne, 2016). En este sentido, los usuarios adaptan prácticas desplegadas en plataformas como Facebook e Instagram, en las que se combina el hábito voyeurístico de consumir «performances de intimidad» con la producción de performances propias. En consecuencia, gran parte de jóvenes suelen construir su identidad a través de performances de intimidad online que gestionan y comparten con sus grupos ampliados de pares.

Además, los rituales amorosos parecen haberse acotado. Así lo observa Molins (2017), quien indica que estas apps promueven la adopción cotidiana de un hábito lúdico e interactivo de exploración de perfiles similar a un videojuego, otorgando un rol activo al usuario, quien ya no solo consume imágenes y textos, sino que toma decisiones que pueden modificar su futuro.

Por su parte, Bergström (2019) señala que las love apps ofrecen espacios 
de sociabilidad íntima separados de la esfera social cotidiana, posibilitando una vivencia de las relaciones sexoafectivas no juzgadas por su entorno cotidiano. Asimismo, permiten la búsqueda ubicua de contactos de manera relativamente anónima, sin exponerse a nivel copresencial, lo que permite cierta «ciber-desinhibición» (Urresti et al., 2015).

Otros autores observan paradojas respecto al uso de estas aplicaciones. Slater (2013) señala que, por un lado, facilitan a las personas conocer a otras con las que podrían ser compatibles. Por otro, la facilidad para conocer gente nueva eleva la exigencia de los usuarios respecto a lo que consideran una buena relación. Esto sugiere mayor inestabilidad en las relaciones y menor tendencia al compromiso.

Los estudios locales sobre la temática aún son incipientes. Pavoni Perrotta (2018) sostiene que, en apps como Tinder, el promedio de chats que se mantienen en paralelo es de cinco. Según la investigadora, el marketing de estas apps apunta a resolver una necesidad romántica más que a proveer sexo casual, porque la preocupación más importante de los sujetos contemporáneos es la soledad. Tanto esta investigadora como Palumbo (2018) coinciden en que el crecimiento de estas apps se explica, en parte, por la alta tasa de divorcios, el crecimiento de los hogares unipersonales y la necesidad de seguir buscando «un otro significativo». Estos fenómenos justifican la importancia de indagar las búsquedas de contactos sexoafectivos mediadas por estas tecnologías.

¿Cuáles son las mediaciones entre los lenguajes de un capitalismo informacional, con sus características de emprendimiento y meritocracia, con los modos de organizar la afectividad y el deseo? ¿Cómo se vinculan las modulaciones de subjetivación experimentados en esta fase del capitalismo con las prácticas de apps de citas? A continuación, se presentan los primeros avances de esta investigación exploratoria.

\section{ANÁLISIS Y RESULTADOS}

A partir de los perfiles analizados, distinguimos tres tipos de estrategias de presentación con fines analíticos, dado que, en las prácticas de los usuarios, 
estas estrategias muchas veces se superponen o combinan. En línea con la teoría de los capitales desarrollada por Bourdieu (1998) y retomada por Hakim (2012), cada una de las estrategias aquí planteadas focaliza en un capital específico: económico, cultural y erótico. Los perfiles combinan la exhibición de distintos capitales, desplegando aspectos económicos, culturales y eróticos como estrategias de seducción. Más allá de las intenciones explícitas de seducir de la mayoría, ¿qué esquemas de percepción, pensamiento y apreciación común expresan?

\subsection{VIAJES, PROFESIONES Y DINERO}

Con capital económico se alude a la exhibición de bienes, servicios, espacios y modos de subjetivación vinculados a una capacidad de compra y a la segmentación de esta capacidad de compra como legitimación de la distinción social. En este artículo se lo circunscribe a la exhibición de ciertos bienes que denotan estatus y una posición privilegiada en el espacio social (Bourdieu, 1998). Si bien nadie exhibe sus extractos bancarios ni su recibo de sueldo, sí presentan indicios de su capacidad de compra. En numerosos sectores sociales, esta capacidad — acompañada de cierto «buen gusto»— se traduce en distinción, que no es tener muchas zapatillas sino unas específicas, que portan cierta fetichización en torno al prestigio de la marca.

Entre los elementos que se observan con frecuencia en la construcción de capital económico distintivo, se encuentran los anteojos negros, autos, motos y bicicletas, vestimenta, accesorios y en particular teléfonos, en todos los casos de gama media o alta. Asimismo, es común la presentación de fotos personales en playas de arena blanca y mar azul, fenómeno también registrado por Palumbo (2018).

Asimismo, son comunes las fotos de plano medio o entero con fondos de íconos turísticos internacionales: la Torre Eiffel, el Puente de Brooklyn, la Estatua de la Libertad o el Cristo de Río de Janeiro. Otros elementos habituales para exhibir capital socioeconómico y turístico son montañas, monumentos históricos, muelles como los del río Delta en el Partido de Tigre del AMBA y ruinas como las de Machu Picchu. Además, estas locaciones 
sugieren capital cultural y permiten desplegar capital erótico, dado que en las vacaciones los usuarios suelen estar más bronceados, relajados y con menos ropa. En numerosas ocasiones, las imágenes se combinan con un texto de presentación que enfatiza estos aspectos:

Viajera por vocación. Fundamentalista del aire acondicionado. (Mujer, 34)

Bailemos hasta que la noche se convierta en un nuevo día. Tengo 40, divorciado, dos hijos. Ser feliz no matter what. Lo fácil es el sexo... Buen vino, viajar... (Varón, 40)

Mi descarga a tierra es viajar seguido a la playa. Disfruto de las cosas simples, las cosas en donde lo material es sin dudas una cuestión de último plano. (Varón, 40)

La centralidad otorgada a los viajes resulta una marca generacional. Las generaciones previas dan más importancia a poseer un auto, representado por la típica foto con el auto detrás. En la actualidad, en cambio, para una significativa parte de jóvenes resulta más seductor una foto con la Estatua de la Libertad o la Torre Eiffel. También lo que exhiben estas fotos es un tiempo de ocio, otro fenómeno generacional: la definición identitaria por el ocio, por la capacidad de mostrarse relajados. Este «capital de relajarse» se relaciona con lo que Illouz (2016) denomina la paradoja central de nuestro tiempo: los mandatos sociales — «trabajá y relajate», «sé eficiente y liberate», «sé racional, pero emocionate» condensan cierta «esquizofrenia» del capitalismo cognitivo-emocional.

Por otra parte, numerosos varones mayores de 35 años aclaran que disponen de capital económico suficiente para proveer comida, bebida y viajes, y que son relativamente exitosos en el mercado laboral. Para ellos, mostrarse «solventes» resulta importante, dado que entienden que la galantería y caballerosidad se plasman en invitar salidas. 
Millonario excéntrico en pesos

Deportista olímpico frustrado

Ciudadano del mundo atornillado acá. (Varón, 39)

Ingeniería, banca financiera. Verdadero caballero. Quiere disfrutar los hermosos momentos de la vida. Entre tanta selva, siempre se encuentra una flor. Por eso te estoy buscando. Hombre de los que ya no quedan. 1,85. Seguro, soltero, sin hijos, espontáneo, sano, divertido. Hace que te olvides de tu billetera. Remonto cualquier situación (velorios, catástrofes, reuniones de consorcio). Dispuesto a compartir. (Varón, 36)

Aquí se observa cierta persistencia de masculinidades hegemónicas (Connell, 1995) ligada al imaginario del «amor romántico», respecto de la solvencia económica como un atributo más masculino que femenino. ¿Qué capitales se les exige a mujeres y a varones? En este punto, se visibilizan usos tensionados de los mandatos de género que aparecen sostenidos, combatidos o matizados por los usuarios. En el caso de las mujeres, la alusión al capital económico suele combinarse con la especificación de qué tipo de relación desean y de su estado civil, dos elementos mencionados con menor frecuencia por los varones. Una gran parte de los perfiles observados muestra que persiste esa distribución tradicional entre «razones»y «sentimientos» para varones y mujeres, como si fuera privativo de las mujeres la explicitación o gestión emocional de los vínculos. No obstante, también se presentan perfiles de varones que explicitan sus virtudes y expectativas afectivas («cariñoso, atento, busco una compañera con quien pasar buenos momentos»; «busco desde una noche de amor hasta la madre de mis hijos»).

Single, sin hijos y con papeles al día-fines serios. Book, curriculum y prontuario x privado. No busco «sexo express». Un proyecto. Hombres caballeros. (Mujer, 34)

Yoga, meditación, psicología. Soltera, sin hijos. (Mujer, 38)

Una polémica en torno al capital económico es quién invita la salida. Con 
la masificación del feminismo, numerosas mujeres desean pagar la mitad de sus consumos; otras consideran que, dado que las mujeres tienden a ganar menos que los varones por la brecha salarial y el «techo de cristal» para el acceso a cargos jerárquicos, no resulta del todo equitativo pagar a medias; mientras que otras siguen creyendo que el varón debe invitarlas para demostrar interés, caballerosidad y galantería. Distintos perfiles de mujeres aclaran que lo que más valoran son las salidas a restaurantes, a bares a tomar cerveza artesanal o «un buen vino», o que aman comer chocolate o tomar helado.

Me gusta comer en lindos lugares. Mex. Per. Sush. Armenia. Tomo cerveza, vino. Me encanta el helado y el chocolate. Si me invitás a algún lugar lindo, no me voy a enojar. (Mujer, 37)

UBA, trabajo en un banco, me gusta caminar, pasear, la música, el cine, series y estar con la gente que quiero. Me gustaría una persona para compartir lindos momentos que disponga de tiempo para mí. Soltera sin hijos. Vegana. (Mujer, 33)

Cirujano UCA. Me encanta conocer gente nueva. Poder compartir un buen café y una magnífica conversación. Me gusta salir a un bar y conocer nuevos lugares. Me encanta la naturaleza y los animales. (Varón, 37)

A veces la escena es un «como si»: las mujeres pueden querer que ellos inviten y negarse por ser feministas, pero que la invitación al menos exista. El varón puede terminar pagando, aunque prefiera que la mujer le ofrezca la mitad y él negarse. ¿Qué expectativas se tramitan respecto de los roles emergentes o tradicionales de género y del manejo del dinero en general? Estas expectativas y tensiones parecen sostenerse con los estereotipos tradicionales. Por otra parte, el trasfondo del dinero también es el intercambio: que la mujer «pague» con sexo la invitación es parte del imaginario social de la transacción. Las interacciones sexoafectivas también experimentan tensiones por la persistencia de imaginarios tradicionales que 
conviven con imaginarios emergentes asociados a la igualdad de género y al feminismo.

Por otro lado, numerosas mujeres aclaran que son autónomas, que cuentan con un significativo capital socioeconómico y cultural que les permite ser independientes y que tienen diversas pasiones e intereses.

Maestría. Posgrado. Licenciatura y todo lo que sea mi pasión. Apasionada, no entiendo otro modo de vivir. Todavía creo en el amor y busco enamorarme de alguien genuino. (Mujer, 30)

Diseñadora gráfica y facilitadora pedagógica en nivel inicial. Llevo 1 semana en esta aplicación. Es divertida. No soy fundamentalista, pero con ideas claras. Las fotos son de reuniones. No me saco muchas. Leo lo q escriben. Los musculosos me intimidan un poco. Jajajaja. Y los zarpados también. (Mujer, 37)

Como señala Illouz (2019), los actores, racionales y emocionales a la vez, calculan el valor de su cita en términos económicos y de entretenimiento y placer, realizando una comparación implícita entre distintos valores: monetario, temporal, energético y emocional. En consecuencia, la mayoría busca tener citas con usuarios de un sector socioeconómico similar o mayor. Esto también suele pretenderse respecto a los capitales cultural y erótico, como se desarrolla en los siguientes apartados.

\subsection{FORMACIÓN ACADÉMICO-PROFESIONAL, CONSUMOS}

\section{CULTURALES E INGENIO}

El capital cultural involucra una serie de estrategias relacionadas con la formación de los usuarios, sus consumos culturales y el modo ingenioso que eligen para presentarse. En primer lugar, la formación alude a títulos universitarios o terciarios, así como a los oficios o actividades artísticas que desarrollan. Los consumos culturales involucran una diversa gama de prácticas, productos y objetos de la cultura contemporánea: música, cine, series, teatro y espectáculos artísticos o musicales, astrología, vino, cerveza, 
marihuana. Por último, y no menos importante, el uso de palabras en distintos idiomas, el ingenio, la creatividad y el humor son valorados como un capital seductor que se enfatiza en frases irónicas, graciosas, críticas o filosóficas.

Como se menciona, una estrategia frecuente es señalar títulos educativos obtenidos o en curso: «futuro médico» (varón, 22); «UADE marketing» (mujer, 24); «casi arquitecto» (varón, 25); «contador 60\% complete» (varón, 26); «Facultad de Derecho UBA» (mujer, 25); «diseñador gráfico» (varón, 30); «ingeniero informático» (varón, 32); «actriz, directora, docente y feminista» (mujer, 38), «diseñadora gráfica en la UBA pero mi verdadera pasión es el arte (dibujo y pinto) mientras trabajo en una multinacional para pagar el alquiler» (mujer, 35).

Como señala Bourdieu (1998), el sistema de enseñanza y la sanción de títulos o credenciales universitarias justifican y legitiman jerarquías sociales. Es por esto que quienes se presentan con un alto capital cultural suelen exigir credenciales educativas y un nivel de escritura similares como requisitos de match.

Hombres profesionales, UNIVERSITARIOS como yo mínimo. El chat eteeerrrno me aburre... dale X si es así. Más ACTITUD y proactividad. Single sin hijos, aunque deseo tenerlos. (Mujer, 36)

Sin ofender, pero si te expresas al estilo «bos», «canzado», «llendo», «sinsero», «comistes» no hay punto de partida. Que escriban más o menos bien, lean, tengan una profesión y sean amables. ¿Pido demasiado? (Mujer, 38)

Asimismo, poseer un título universitario y una profesión no siempre se traduce en un capital económico medio o alto. Por otra parte, esto se juega de distintos modos en varones y mujeres en relación con los paradigmas sexogenéricos tradicionales y emergentes. A las mujeres suelen resultarles interesantes los varones con alto o medio capital cultural, mientras que una significativa parte de los varones prefiere que ellas posean mayor capital erótico, pero no los superen en capitales culturales y económicos. 
Otra estrategia para seducir consiste en especificar referencias artísticas, sea como productor, consumidor, o ambas. Estas forman parte de la exhibición de capital cultural, como se muestra en las siguientes presentaciones de perfiles:

Cinéfilo, aficionado al teatro y adicto al café. El mundo anda apurado y yo a contramano. (Varón, 33)

Crítico de cine, periodista y profesor (pero no pobre). Lo que más me gusta es charlar. Tengo dos gatos y tres sobrinos, estrellas de mi Instagram. Busco desde una noche de diversión hasta la madre de mis hijos y todo lo que hay en el medio. (Varón, 36)

Controladora de ventas. Mujer de carácter, que sabe lo que quiere y adónde va. Me gusta el teatro, una buena charla, un libro acompañado de una copa de vino. Será que se podrá conocer alguien interesante? IMPORTANTE: abstenerse los básicos en búsqueda de sexo, se necesita más que una cara bonita y un cuerpo dibujado. (Mujer, 30)

Asimismo, los consumos culturales se evidencian en las referencias musicales, que pueden ir desde el usuario tocando un instrumento hasta la referencia a bandas, estilos y canciones preferidas. Para esto, un recurso suele ser la integración de los consumos musicales en Spotify y un «himno musical», que es una canción elegida por el usuario para presentarse.

Nerd, nerd, nerd. Procrastinación a full con series, pelis, rock, grunge, country, ah y cerveza (varón, 26); leer filosofía, cocinar/comer, tech house/progre (varón, 27); permacultura, vegetariano, de techno a música clásica (varón, 28); abogada de profesión, melómana por vocación: música, alternativa, jazz, rock, blues, funk, grunge! (mujer, 28); no vivo sin música (amante del jazz frank sinatra) (mujer, 30).

En términos de consumos, también es frecuente la mención a la cerveza, vino, tragos $\mathrm{y}$, en menor medida, a la marihuana, como estrategia de 
mostrarse relajado. Algunos señalan en su presentación el número 420, referencia velada al cannabis.

Porro. Birra. Rap (varón, 18); buena onda, conversadora, geminiana, sencilla (mujer, 32); piscis, ingeniero, jugador amateur de tenis (varón, 34); en una relación abierta. Salir a quemar uno y tomar unos mates o una birra (varón, 30); fotógrafo. 420. Ley de atracción — reiki— traveller libriano (varón, 29); alimentación natural, fumo y NO tomo alcohol, 420 (mujer, 40).

Dentro del capital cultural, otra dimensión es la de presentar conocimientos de astrología. En ocasiones, especifican su signo, ascendente y luna, y aclaran que buscan personas afines y compatibles (refiriendo al estado civil y también al zodíaco).

Soy de Acuario con luna en Acuario y ascendente en Aries. Me gusta la meditación, la música, la gente despierta, inteligente, sabia (mujer, 30); apasionada por la cocina y el baile! Leonina y de las buenas! (mujer, 38); tengo luna en escorpio, soy de cáncer y ascendente géminis: me interesa que seamos compatibles (mujer, 40); tomo mate. No tomo alcohol y no fumo. Signo? Tauro. Ascendente? Aries, jaja (varón, 26).

Otro recurso para mostrar capital cultural es presentarse con una frase de índole filosófica, propia o ajena, que denote cierta profundidad reflexiva en torno a la existencia humana.

Suerte es darse cuenta de las cosas (varón, 24); la humildad es clave, no se conecta mentalmente con cualquiera (mujer, 28); no existen manuales de vida (mujer, 28); hagamos que cada día valga la pena (mujer, 29); actitud ante todo (mujer, 30); importa mucho más lo que piensas de ti que lo que otros piensan de ti (mujer, 31); no me tomo en serio las cosas que no me hacen reír (mujer, 34); dicen que el que busca encuentra, pero no siempre lo que estaba buscando (mujer, 35); un día sin risa es un día perdido (varón, 26).

A su vez, de entre quienes no optan por la exclusiva estrategia de 
construcción de corporalidad erótica, una significativa parte elige el humor:

Mis fotos tienen photoshop, en realidad soy albina y gorda (mujer, 31); no nos ganan los abdominales sino el sentido del humor (mujer, 34); si no te parecés al de la foto, pagás la birra hasta que empieces a parecerte (mujer, 35); tengo unos rulos divinos pero con humedad... q difícil se vuelve todo. Medio ciega pero mis lentes tienen mucha onda (mujer, 35); sí, estoy comiendo un pancho en el piso del furgón del tren y podría hacerlo toda mi vida (mujer, 19); de vuelta en Tinder, maldita sea (mujer, 26); Tinder son los padres (varón, 27); esta app me hace doler el dedo (mujer, 28); mi mamá dice que soy súper (mujer, 28); en realidad, busco chongo con perro (mujer, 28); empecé crossfit hace 2 semanas y me duele la vida (mujer, 29); alguien q me haga borrar esta app definitivamente?? (mujer, 33).

Algunos optan por realizar comentarios ingeniosos en torno a la vida, las relaciones sexoafectivas y la app. En numerosos casos, más allá de su dirección de Instagram, no escriben nada, o solo una frase ingeniosa. Algunos únicamente ponen entre una y tres fotos personales, a veces imágenes de atardeceres, mascotas, animaciones, memes o grafitis. Estos suelen apelar a una modalidad minimalista, al misterio o a la sofisticación, en ocasiones sugiriendo un consumo autoirónico de Tinder.

El primer tipo de presentación de capital cultural es el más evidente y tradicional, dado que asocia cultura con educación formal y acreditaciones. El segundo es más generacional juvenil y corresponde al imaginario posterior que emerge en el último tercio del siglo XX: relaciona capital cultural con el espectro de consumos culturales contemporáneos, vinculando estar en pareja con compartir bibliotecas, películas, series y salidas culturales y, de manera reciente, coincidir en plataformas de lectura y streaming, así como escuchar música afín vía Spotify y Youtube. Para las generaciones nacidas hasta la primera mitad del siglo $\mathrm{XX}$, la afinidad del gusto musical no era un requisito. El tercer tipo de capital cultural resulta el más sutil porque se vincula a la seducción, en el sentido del uso ingenioso y creativo de recursos, consumos y estrategias. 


\subsection{EL EROTISMO $\quad$ Y $\quad$ LA ENTRONIZACIÓN DE LA}

\section{CORPORALIDAD DESEABLE}

El capital erótico (Hakim, 2012) refiere a la exhibición de una corporalidad deseada, en línea con los cánones de belleza contemporáneos difundidos por los medios masivos de comunicación a través de la publicidad, la televisión, el cine, las series online e Internet. Si bien coincidimos con Hakim en que este fenómeno se observa más acrecentado en las mujeres, generalizamos su uso también para varones, aunque las exigencias de estos capitales difieran sexo-genéricamente para unos y otros.

Ambos son deseados en gran medida de acuerdo con su cercanía con los cánones de belleza contemporáneos: delgadez, altura, vestimenta que resalten la atractividad y corporalidades tonificadas. Esto se conecta con lo que señalan Margulis y Urresti (1996) acerca del prestigio social de lo juvenil, que mueve a numerosas personas, en particular de sectores urbanos de clases medias y altas, a incorporar a su corporalidad signos de juvenilidad en pos de elevar su atractivo y estatus.

A diferencia de quienes centran su presentación en el capital cultural, quienes desarrollan estrategias vinculadas a la construcción de una corporalidad deseable utilizan recursos que van desde retoques estéticos, efectos, filtros de Snapchat o Photoshop hasta animaciones y recortes. Si bien el capital erótico o de «atractividad» históricamente ha resultado central en la búsqueda juvenil de parejas, el actual peso decisivo de este capital forma parte de una vida más «líquida», con más obstáculos internos que externos para la búsqueda del amor y la pareja.

Como señalan Ward (2017) y Gómez Beltrán (2019), las fotos personales se eligen en un intento de presentar un yo ideal pero auténtico, con el objetivo principal de mostrarse físicamente atractivos, pero también para sugerir otros indicadores como el nivel socioeconómico o educativo. Al mismo tiempo, pretenden persuadir a las audiencias de usuarios para establecer el contacto esperado y aspiran a ser coherentes con su perfil y con sus performances en conversaciones privadas. Partiendo de una zona geográfica cercana o afín que facilita la $a p p$, los usuarios estudian perfiles no solo en busca de personas que 
les gusten, sino también en busca de pistas sobre cómo presentarse para atraer a otros similares a ellos, así como para lograr seducir a perfiles con una deseable corporalidad, rango etario y sector social.

En particular en menores de 30 años, se observan fotos que emulan el estilo erótico del pornosoft. En la búsqueda de ser populares (ahora en Instagram, ya no en Facebook, para los menores de 30), de tener numerosos matches, se realizan performances de intimidad erótica con el objetivo de seducir. Una significativa parte de los mayores de 35 años publican fotos personales editadas, o de hace unos años, cuando eran más jóvenes. Esto promueve una mayor brecha entre la interacción y seducción digital, y los potenciales encuentros sexoafectivos copresenciales. Retomando la línea de Baudrillard (1978), quien advirtió de modo pionero que la imagen de las pantallas se torna hiperreal, «más real que lo real», Han señala lo siguiente:

Hoy las imágenes no son sólo copias, sino también modelos. Huimos hacia las imágenes para ser mejores, más bellos, más vivos. (...) El medio digital consuma aquella inversión icónica que hace aparecer las imágenes más vivas, más bellas, mejores que la realidad, percibida como defectuosa. (2014: 49)

Una usuaria de 28 años, por ejemplo, publica cuatro imágenes: dos selfies sonriendo maquillada con musculosa y escote, una foto de plano medio en una discoteca y otra selfie en una reposera con lentes negros de una marca distinguida. Otra usuaria de 29 años publica seis imágenes: una selfie sonriendo en un sillón, una de plano medio en bikini tomando sol, dos riendo con amigas y la última de plano entero tomando sol con remera, calzas y lentes negros junto a un lago. En los perfiles relevados predomina la publicación de fotos en las que buscan destacar la belleza, el atractivo físico, la vitalidad, la frescura y la vida social junto a los grupos de pares. Tanto mujeres como varones señalan que quienes más «piel» exponen suelen ser quienes más matches consiguen.

Por otra parte, quienes construyen perfiles con altos niveles de juvenilidad y capital erótico suelen demandar capitales similares. Por ejemplo, una entrevistada advierte que es selectiva con los likes, y solo likea 
a perfiles menores de 30 años, delgados y que parecen altos. Si no lo aclaran en su perfil, suele preguntarles cuánto miden. Un entrevistado cuenta que, en un chat, le preguntó a una mujer que no tenía fotos de cuerpo entero en su perfil si «le habían cortado las piernas». Numerosos varones demandan fotos de cuerpo entero para poder visualizar la figura de la mujer con la que interactúan.

En ocasiones, algunos que portan un alto capital erótico buscan conocer personas con mayor capital cultural y económico. Por ejemplo, una mujer de 20 años de un barrio humilde del sur de Buenos Aires utiliza Tinder en el barrio de su hermana de la Zona Norte para interactuar con perfiles que tengan mayor capital económico que los de su barrio.

Dentro de quienes eligen centrar su estrategia de presentación en la construcción de capital erótico, es frecuente la mención a los atributos físicos (altura y contextura: «atlético, delgado, musculoso») y a los hábitos saludables: actividad física, deportes, fútbol, tenis, gym, cross-fit y, en particular en mayores de 35, alimentación vegana, meditación y yoga.

Trabajo, estudio, 1,82. Tauro. Si hablás primero, no va a cambiar el universo. Es probable que conteste más al Instagram (varón, 24); actor, modelo publicitario, personal trainer, masajista matriculado y traumatólogo (varón, 26).

$1,72 \mathrm{mts}$. de entusiasmo y garra, amor por el yoga, crossfit, acroyoga y nuevas disciplinas. Farmacéutica de profesión y centrada en la salud ayurveda. Prefiero salir a pasear en bici o caminar antes que encontrarte en un boliche. (Mujer, 29)

Otros recursos frecuentes son mostrar el rostro maquillado, sonreír, posar junto a espejos, seleccionar fotos de su mejor perfil o momento, usar escote en fotos de plano medio, americano y entero; en plano picado y contrapicado. En numerosos casos, estas usuarias mencionan cierta expectativa de altura como requisito físico: «al menos 1,80»; «no busco al príncipe azul pero al menos $1,75 »$. 
Por su parte, los varones que eligen centrar su estrategia de presentación en la construcción de capital erótico frecuentemente eligen al menos una foto con el torso desnudo (en la playa o en el gimnasio) o con ropa ajustada, copiando ciertas estrategias femeninas; a veces también mencionan sus atributos físicos, así como lo que buscan en sus potenciales citas («con buena cola», «busco mujeres atractivas para pasarla bien»; «chicas sexies y $\sin$ rollos»).

La confluencia de estos tres capitales observados muestra que, en el capitalismo contemporáneo, la gestión del yo, vinculada a la exhibición regulada y calculada de sí mismo vía plataformas de redes sociales, se exacerba en las apps de citas, donde ya no solo se busca un «me gusta» generalizado, sino un concreto like de una pareja potencial. Así, las elecciones sexoafectivas tienden a equipararse a elecciones inmediatas de consumo.

\section{DISCUSIÓN Y CONCLUSIONES}

A lo largo del artículo se han descripto tres tipos comunes de presentaciones en Tinder que fueron observados en la muestra. En primer lugar, quienes centran su estrategia en el capital económico, presentado principalmente mediante su capacidad de relajarse y vivir aventuras vinculadas a viajes a playas, montañas, lugares alejados o exóticos y elementos que portan distinción social. En segundo lugar, quienes centran su estrategia en exhibir su capital cultural, sugiriendo o explicitando su distinción social desde ciertas credenciales, saberes, consumos culturales, prácticas artísticas y frases ingeniosas. En tercer lugar, quienes centran su estrategia de presentación y seducción en la construcción de una corporalidad con alto capital erótico. Para esto, producen y editan sus fotos personales con dedicación, concentrándose en combinar características estético-corporales de alta atractividad, prácticas físico-deportivas y hábitos saludables.

Con el objetivo de generar deseo, pero también misterio e interés, muchos combinan las tres estrategias, intercalando en su presentación referencias a su capital económico, cultural y erótico. El capital social, referido a la red de contactos, es el menos presente. No obstante, en ocasiones se sugiere o intuye 
a través de las fotos con amistades o conocidos, los lugares en los que se tomaron las fotos presentadas y las instituciones de pertenencia señaladas en el perfil.

Vinculado a los capitales, los tipos de usuarios también pueden clasificarse según sus búsquedas declaradas: los «sexuales» buscan exclusivamente encuentros eróticos sin interés aparente en intercambios afectivos, intelectuales o socioculturales; los «sociabilizadores» priorizan compartir momentos agradables sin fines predeterminados; los «lúdicos» juegan con la app para entretenerse, sumar matches y elevar su autoestima, por lo general sin concretar encuentros presenciales; los «voyeurs» reducen su interacción a mirar perfiles y dar likes, sin siquiera colocar una foto personal; los «románticos» aspiran a enamorarse y encontrar pareja; los «cultos» buscan compartir experiencias artísticas, saberes, salidas y consumos culturales; los «gourmet» aspiran a encontrar con quien compartir diferentes tipos de cocina y bebidas; los «viajeros» esperan encontrar un compañero de aventuras; los «familieros», una pareja con quien tener hijos o compartir una familia ensamblada. En numerosos casos, los usuarios combinan varios de los tipos de intereses mencionados.

El crecimiento de Tinder podría explicarse por su extendida asociación, en el imaginario, a un bar o una discoteca siempre abierta, con una tarifa accesible para todos. Además, permite generar contactos y planificar encuentros desde la comodidad del teléfono y desde donde se esté: hogar, trabajo, estudio, transporte, club o sala de espera. Por un lado, resulta cómodo para especificar los requerimientos pretendidos y facilita la búsqueda de perfiles de modo ubicuo; por otro, también permite concluir con el vínculo antes de que se desarrolle, evitando la confrontación presencial.

En línea con Sumter et al. (2017), se evidencia que las razones para utilizar la app abarcan desde el entretenimiento lúdico-comunicativo que genera, la excitación emocional y el impulso de autoestima que provoca, la facilidad de uso, el deseo de conocer gente y de experimentar y vivir experiencias sexoafectivas, hasta la motivación supuestamente central: búsqueda de pareja, que a veces incluye la proyección de compartir un hogar 
y formar una familia. Para la amplia mayoría, estas motivaciones se combinan y varían con el tiempo.

En su flujo permanente de fotografías y mensajes, estas apps permiten combinar el rol de observador con el de observado, de sujeto y objeto de deseo. En este sentido, democratizan la posibilidad de búsqueda y la esperanza de que, con una combinación de «suerte», «paciencia»y habilidad para construir el perfil, se logre hallar al otro deseado. No obstante, algunos usuarios confiesan que, pasados los primeros meses de entusiasmo con Tinder, les genera frustración ante la dificultad para entablar vínculos satisfactorios. En consecuencia, muchos la desinstalan de su teléfono hasta que, luego de unos meses, vuelven a instalarla.

En este sentido, la estetización del self en jóvenes y sus interacciones online tienden a tornarse más relevantes que los encuentros copresenciales. Desde la zona de confort que provee el ecosistema de las plataformas digitales y apps, millones de jóvenes reducen sus experiencias sexoafectivas a sus presentaciones e interacciones digitales, mediadas por intermitentes encuentros copresenciales. En este contexto de hiperestimulación digital del tiempo de ocio, se advierte cierta demanda colectiva de intensidad en los encuentros que surjan de las dating apps: «Si voy a salir de mi cueva digital y de la comodidad de mi grupo de pares para aventurarme al mundo presencial con algún desconocido — parecen decir al unísono-, espero que sea una experiencia intensa o al menos interesante».

Aun con sus limitaciones, apps como Tinder tienen la propiedad de seducir, entretener, estimular el deseo y, como señala Palumbo (2018), reerotizar a sus usuarios: sean jóvenes posadolescentes en busca de expandir sus experiencias sexuales, treintañeros que aspiran a compartir su vida con un otro significativo o jóvenes adultos en torno a los cuarenta años que, tras ser padres o madres y separarse, buscan recuperar parte de su autoestima volviendo al mercado sexoafectivo. En todo caso, hemos relevado de modo exploratorio algunas dimensiones comunes y en particular la centralidad que gran parte de los jóvenes otorgan a la estetización de los perfiles y a la construcción de una corporalidad atractiva por sobre otros campos de sentido. 
Protagonistas y al mismo tiempo voyeurs de su «propia» sitcom eróticaromántica, los usuarios de estas apps se convierten en prosumidores de episodios sexoafectivos que narran a amistades y familiares tanto como a sí mismos. Estas experiencias forman parte del material de conversación de sus chats con amistades y candidatos, así como de sus nuevas citas, en un intercambio de información y accountability, mientras prosiguen en búsqueda del match perfecto.

RECIBIDO: 11 DE NOVIEMBRE DE 2018

ACEPTADO: 8 DE ABRIL DE 2019

\section{BibLIOGRAFÍA}

BAUDRILlARD, J. (1978). Cultura y simulacro. Barcelona: Kairós.

BAUMAN, Z. (2013). La cultura en el mundo de la modernidad líquida. Buenos Aires: Fondo de Cultura Económica.

BECK, U. y BECK-GERNSHEIM, E. (2012). Amor a distancia: nuevas formas de vida en la era GLOBAL. BARCELONA: PAIDÓS.

Bergström, M. (2019). Les nouvelles lois de l'amour

Sexualité, couple et rencontres au temps du numérique. París: La decouverte. Bourdieu, P. (1998). La Distinción. Criterio y bases sociales del gusto. Madrid: Taurus.

BoyD, D. (2014). It's Complicated: The Social Lives of Networked Teens. New Haven: Yale University Press. https://bit.ly/2IxtlQI

Butler, J. (2005). Cuerpos que importan. Sobre los límites materiales y discursivos del «sexo». Buenos Aires: Paidós.

Connell, R. (1995). Masculinities. Cambridge: Polity Press.

Foucault, M. (2008). Historia de la sexualidad. Buenos Aires: Siglo XXI.

GidDEnS, A. (1995). Modernidad e identidad del yo. Barcelona: Península.

GÓMEZ BELTRÁN, I. (2019). Grindr y la masculinidad hegemónica: aproximación comparativa al rechazo de la feminidad. Estudios Sociológicos, 37(109), 39-68. 
https://dx.doi.org/10.24201/es.2019v37n109.1644

HAKIM, C. (2012). Capital erótico. El poder de fascinar a los demás. Barcelona: Debate.

HAN, B. (2014). En el enjambre. Buenos Aires: Herder.

HINE, C. (2012). The Internet: Understanding Qualitative Research. Nueva York: Oxford.

IllouZ, E. (2019). Capitalismo, consumo y autenticidad. Las emociones como mercancía. Madrid: Katz. . (2016). Por qué duele el amor. Una explicación sociológica. Buenos

Aires: Katz.

LinNe, J. (2016). La multimidad. Performances íntimas en Facebook de adolescentes de Buenos Aires. Estudios sociológicos, 100(34), 65-84.

Marra e Rosa, G., Rodrigues dos Santos, B., Stengel, M. y Helena de FreITAS, M. (2016). Estetización del self en redes sociales: contradicciones humanas y producción subjetiva contemporánea. Revista de Psicología (PUCP), 34(2), 313-336. doi: 10.18800/psico.201602.004

Margulis, M. y UrResti, M. (1996). La juventud es más que una palabra. En M. MArgulis (Ed.), La juventud es más que una palabra (pp. 1330). Buenos Aires: Biblos.

MoORE, L. (2015). Gracias por la compañía. Buenos Aires: Seix Barral.

Molins, A. (2017). La tinderización del amor. La Vanguardia, 14-10-17. Disponible en: https://bit.ly/2Qic0LI.

Morduchowicz, R. (2012). Los adolescentes y las redes sociales. Buenos Aires: Fondo de Cultura Económica.

Palumbo, M. (2018). Motivaciones y expectativas en las búsquedas de vínculos eróticos y/o afectivos. Cultura y representaciones sociales, 25(1), 184-213.

Pavoni Perrotta, F. (2018). Tecnificación y afectividad: el ideal romántico en las publicidades de Tinder y Happn: representaciones sobre la búsqueda de un otro en el mercado del deseo. Buenos Aires: Universidad de Buenos Aires. Disponible en: https://bit.ly/2NH6BO0 
Rosenfeld, M. y Reuben, T. (2012). Searching for a Mate: The Rise of the Internet as a Social Intermediary. American Sociological Review, 77(4), 523-547.

Sibilia, P. (2008). La intimidad como espectáculo. Buenos Aires: Fondo de Cultura Económica.

Sumter, S., VAndenbosch, L. y LigtenberG, L. (2017). Love me Tinder: Untangling emerging adults' motivations for using the dating application Tinder. Telematics \& Informatics, 34(1), 67-78. doi: https://bit.ly/2xPhpTI.

Urresti, M., Linne, J. y BAsile, D. (2015). Conexión total. Los jóvenes y la experiencia social en la era de la comunicación digital. Buenos Aires: Grupo Editor Universitario.

WARD, J. (2017). What are you doing on Tinder? Impression management on a match making mobile app. Information, Communication \& Society, 20(11), 1644-1659. doi: http://doi.org/ct9k. 